This item was submitted to Loughborough's Research Repository by the author.

Items in Figshare are protected by copyright, with all rights reserved, unless otherwise indicated.

\title{
UHTC composites for hypersonic applications
}

PLEASE CITE THE PUBLISHED VERSION

PUBLISHER

(C) The American Ceramic Society

VERSION

VoR (Version of Record)

LICENCE

CC BY-NC-ND 4.0

\section{REPOSITORY RECORD}

Paul, Anish, Daniel Doni Jayaseelan, Saranya Venugopal, E. Zapata-Solvas, J.G.P. Binner, Bala Vaidhyanathan, A. Heaton, Peter M. Brown, and W.E. Lee. 2012. "UHTC Composites for Hypersonic Applications". figshare. https://hdl.handle.net/2134/9676. 
This item was submitted to Loughborough's Institutional Repository (https://dspace.lboro.ac.uk/) by the author and is made available under the following Creative Commons Licence conditions.

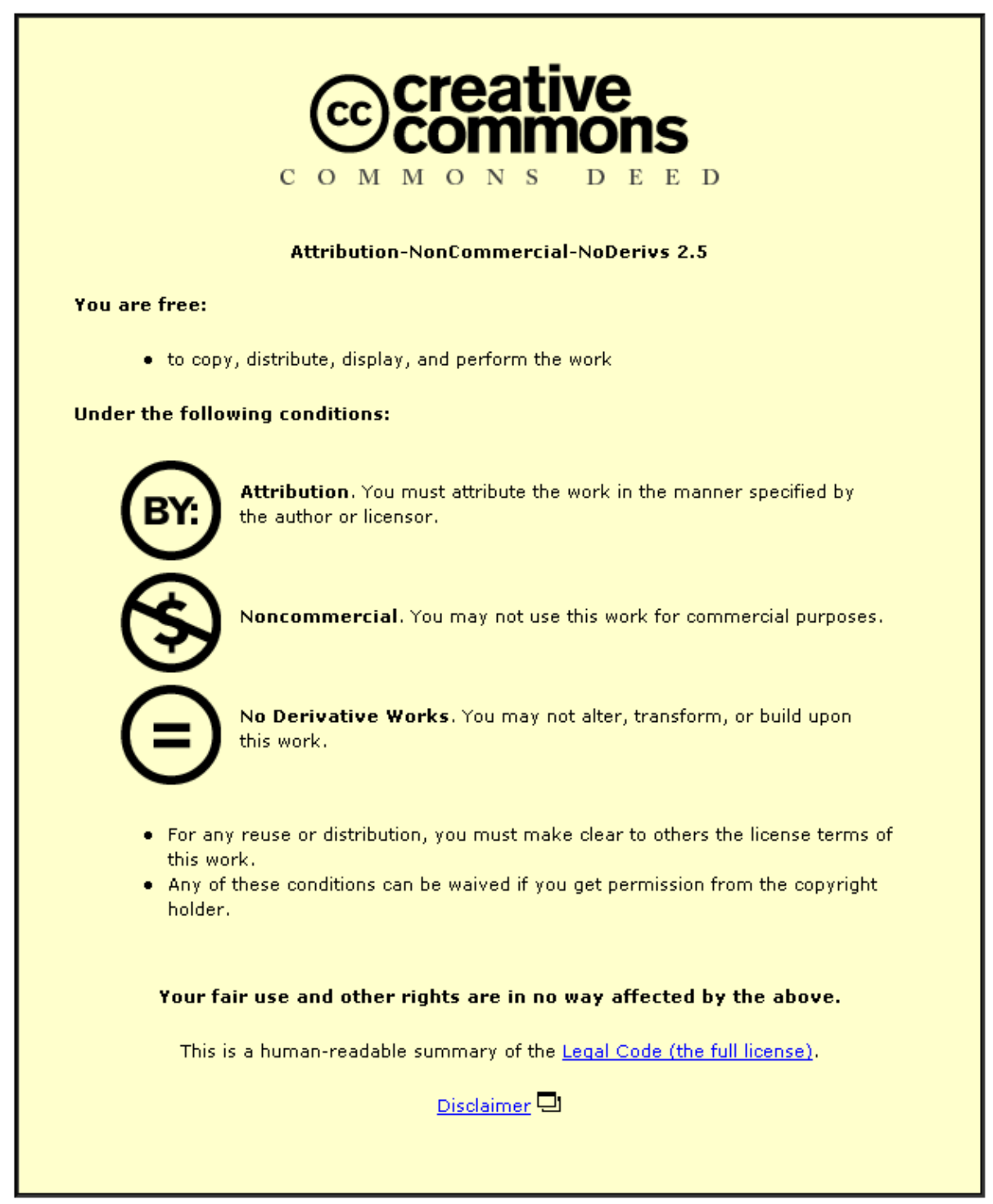

For the full text of this licence, please go to: http://creativecommons.org/licenses/by-nc-nd/2.5/ 


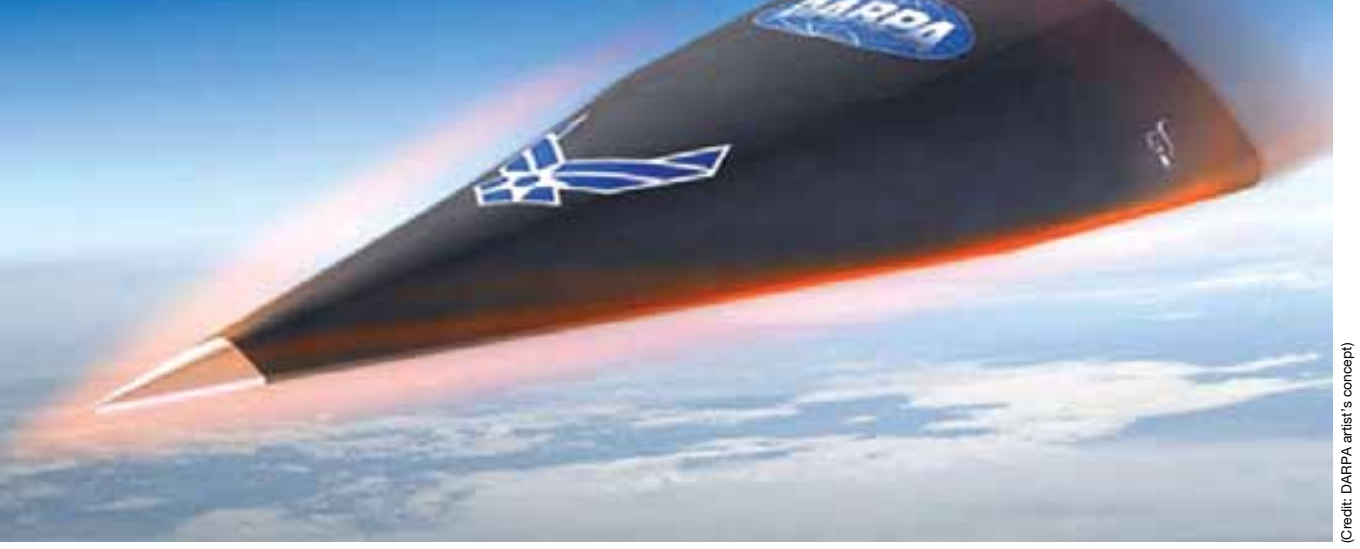

4 Figure 1 USAF Falcon Hypersonic Space Vehicle.
A. Paul, D.D. Jayaseelan, S. Venugopal, E. Zapata-Solvas, J. Binner, B. Vaidhyanathan, A. Heaton, P. Brown and W.E. Lee

\section{O bulletin cover story}

\section{UHTC}

composites

\section{forhypersonic applications}

Refractorynon-oxidesprotectleadingedges of hypersonic vehicles during flight.

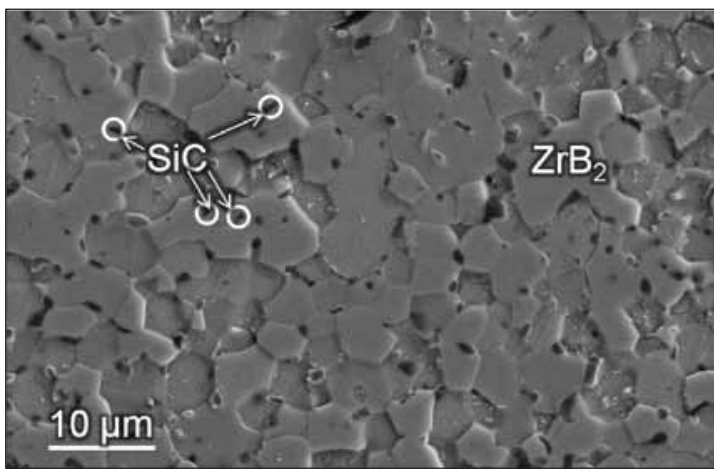

Figure 2 Microstructure of $\mathrm{ZrB}_{2}-5$-volume-percent $\mathrm{SiC}$ composite.

\section{$A_{\text {many scien- }}^{\text {dream for }}$} tists, engineers and sci-fi enthusiasts is of an aerospace vehicle that can take off from an airport, fly through the atmosphere and travel to the other side of the earth at hypersonic speeds, and then return through the atmosphere to the same or another airport. Thanks to programs like DARPA's Falcon Hypersonic Technology Vehicle 2 program (Figure 1), the dream is taking form.

Hypersonic vehicles need sharp leading edges to enable vehicle manoeuvrability during atmosphere exit and re-entry. The edges will see temperatures well in excess of $2000^{\circ} \mathrm{C}$ and be hit with corrosive plasmas from the atmosphere at ablative speeds. Other challenges associated with these conditions include severe oxida- tion, extreme heat fluxes and high mechanicalstresses. 'Components, such as the leading edges, combustors and thermal protection systems, thus require materials that can withstand the high thermal, mechanical and shock-wave loadings that these aircraft will experience during flight. Such demanding requirements limit the field of possible materials to ultra-hightemperature ceramics. These are typically non-oxides with melting/decomposition temperatures in excess of $3000^{\circ} \mathrm{C}$. Examples include borides, nitrides and carbides of Group IV-V metals in the periodic table, such as $\mathrm{ZrB}_{2}, \mathrm{HfB}_{2^{\prime}}$ $\mathrm{ZrC}, \mathrm{HfC}, \mathrm{TaC}$ and $\mathrm{HfN}^{2,3}$

Development of non-oxide ceramics has lagged behind that of oxides because they are rarely found in nature, need to be processed in controlled reducing atmospheres and tend to oxidize in air even at room temperature, especially when in fine powder form. As a result, the understanding of their crystal chemistry and the processing-microstructureproperty relations is nowhere near that of, for example, simple oxides, silicates, phosphates and complex oxide systems. Fulfilling this dream will require a revolution in aviation with a key challenge being the vehicle thermal protection 
system in which UHTCs will have a crucial role.

\section{Early work on UHTCs}

Bulk single-phase UHTCs for these high-temperaturestructuralapplications are limited by their poor oxidation and ablation resistance as well as poor damage tolerance. ${ }^{4-7}$ Research efforts have focused on improving the oxidation and thermomechanical properties, but such studies need to expand the boundaries of property measurement capability because the service temperatures and heat fluxes are so high. Various densification routes, including hot pressing, pressureless sintering, self-propagating high-temperature synthesis, reactive hot pressing and spark-plasma sintering, ${ }_{1}^{8}$ have been investigated to optimize fabrication proceduresand performance of UHTCs.

Development of composite UHTC systems hasfocused on particulate additions, particularly of $\mathrm{SiC}$ at approximately 20 volume percent, because it significantly improves oxidation resistance at temperatures up to $1500^{\circ} \mathrm{C}$ by forming a protective amorphous, liquid borosilicate coating. ${ }^{9}$ There have been many previous attempts to improve the oxidation resistance of $\mathrm{ZrB}_{2}-\mathrm{HfB}_{2}$ ceramics by, for example, increasing the viscosity of the liquid silica layer, increasing the immiscibility of different liquid phases or by developing dense $\mathrm{ZrO}_{2}$ layers via liquid-phase sintering to reduce oxygen penetration and diffusivity. ${ }^{8}$ However, in hypersonic applications, the temperature often exceeds $2000^{\circ} \mathrm{C}$ in combination with severe airflow. In such extreme conditions, any molten liquid will be blown off, rapidly exposing the underlying layer leading to further oxidation and UHTC recession.

\section{UHTC development: Chemistry, processing and properties}

Initial research at Imperial College, London aimed to develop solid refractory oxide protective layers by adding rare-earth borides or oxides to a baseline $\mathrm{ZrB}_{2}$-20-volume-percent-SiC (known as ZS20) UHTC. ${ }^{10}$ However, it is clear that if satisfactory thermal protection performance is to be achieved in the severe conditions encountered, innovative and step-changing approaches are needed. A collaborative UK program between Loughborough University and Imperial College is attempting to find some of these approaches.

The work at Imperial hasfocused on processing dense monolithic UHTC systems using SPS and measuring properties at increasingly high temperatures, while that at Loughborough has been aimed at incorporating UHTC powders into carbon-fiber preforms and evaluating the hightemperature oxidation performance. Current work is focused on developing composite systems by joining the two systems together with concomitant protective oxide layer formation. The work is being undertaken in collaboration with the United States Air Force Research Laboratory's Materials and Manufacturing Directorate, whose UHTC research focuses on developing a physical model to understand the oxidation mechanisms of zirconium and hafnium diboride-based ceramics and on developing UHTC composites reinforced with silicon carbide fibers. ${ }^{11}$

A series of fully dense $\mathrm{ZrB}_{2}{ }^{-}, \mathrm{HfB}_{2}{ }^{-}$ and TaC-based UHTC composites has been fabricated using the SPS facility at Queen Mary University, London. Figure 2 shows a typical microstructure of a 5-volume-percent-SiC-reinforced $\mathrm{ZrB}_{2}$ composite sintered at $1900^{\circ} \mathrm{C}$, revealing a dense microstructure with no visible cracks or pores. The grey grains forming the matrix are $\mathrm{ZrB}_{2^{\prime}}$ the mean grain size is less than 5 -micrometers, and the grains are faceted. The dark grains are $\mathrm{SiC}$ and they predomi- nantly occur as less than 1-micrometer intergranular inclusions.

$\mathrm{HfB}_{2}$-based ceramics are more difficult to densify and must be sintered at temperatures at least $100^{\circ} \mathrm{C}$ higher than their $\mathrm{ZrB}_{2}$ counterparts. Figure 3 shows SEM and TEM images of $\mathrm{HfB}_{2}-20$ volume-percent-SiC-5-weight-percent$\mathrm{LaB}_{6}$ (HS20-5-weight-percent LaB ) composites sintered at $2000^{\circ} \mathrm{C}$.

Coefficients of thermal expansion measured from room temperature to $2000^{\circ} \mathrm{C}$ showed that monolithic $\mathrm{ZrB}_{2}$ had the highest CTE with a value of $7.8310^{-6} \mathrm{~K}^{-1}$. This was slightly higher than that of monolithic $\mathrm{HfB}_{2}$ at 7.63 $10^{-6} \mathrm{~K}^{-1} . \mathrm{SiC}$ and all other additions investigated reduced the CTE values below the values of the baseline UHTC matrices. For all UHTC composites, however, the CTE increased from 5.5 $\times 10^{-6} \mathrm{~K}^{-1}$ at $200^{\circ} \mathrm{C}$ to $7 \times 10^{-6} \mathrm{~K}^{-1}$ at $2000^{\circ} \mathrm{C}$. The relatively large CTE values for UHTCs compared with more traditional thermal protection materials, such as the silica-based tile (CTE of $4.2 \times 10^{-6} \mathrm{~K}^{-1}$ ) used by the space shuttles, present a number of design 


\section{UHTC composites for hypersonic applications}

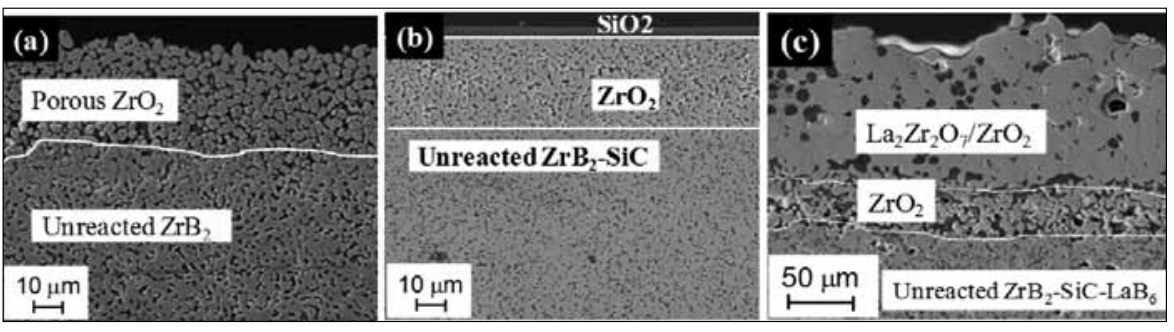

Figure 5 Cross-section microstructures of (a) $\mathrm{ZrB}_{2^{\prime}}$ (b) ZS20 and (c) ZS20-LaB ${ }_{6}$ oxidized for 1 hour at $1600^{\circ} \mathrm{C}$.
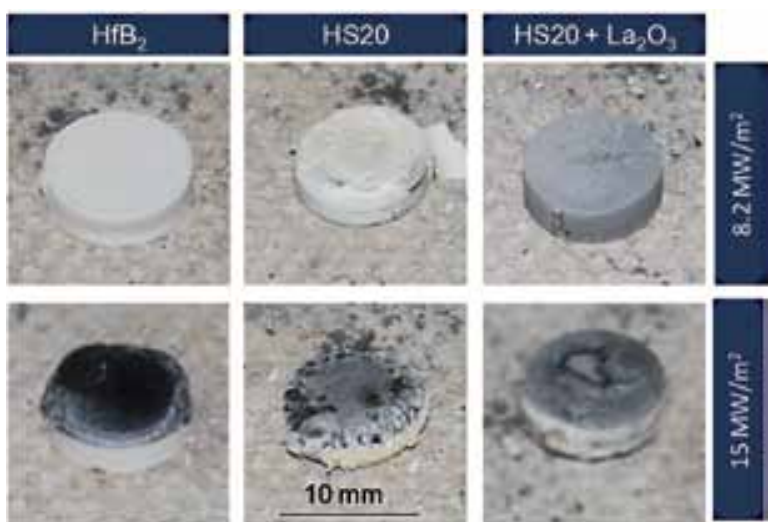

Figure 6 Photographs of $\mathrm{HfB}_{2}$-based UHTCs tested for 60 seconds at 8.2 and 15.2 megawatts per square meter using a defocused $\mathrm{Nd}$ :YAG laser.

challenges. The large CTE makes the materials significantly less resistant to thermal shock and, hence, makes it difficult for designers, who need to account for the different CTEs of multipart components to prevent cracking caused by constrained expansion on heating.

Thermal diffusivities (Figure 4) were measured during heating using the laser flash diffusivity technique. $\mathrm{ZrB}_{2}$ and $\mathrm{HfB}_{2}$ had the highest diffusivity values, approximately 40 square millimeters per second, at room temperature, while their lowest values, 10 and 15 square millimeters per second, respectively, occurred at $1900^{\circ} \mathrm{C}$, the highest temperature at which measurements were undertaken. Additions of $\mathrm{SiC}$ and $\mathrm{La}_{2} \mathrm{O}_{3}$ decreased the thermal diffusivity by at least 10 percent. A plausible explanation for this is the formation of microcracks between grains, as occurs in many polycrystalline materials manufacturedbyhigh-temperaturesintering processes, where thermal expansion mismatch between adjacent grains can lead to stresses on cooling.

Microcracking is known to degrade thermal properties in ceramics, and
Monteverde ${ }^{12}$ has documenteddebondingbetween $\mathrm{HfB}_{2}$ and $\mathrm{SiC}$ grains as well as microcracked $\mathrm{HfB}_{2}$ grains in reactive hot-pressed $\mathrm{HfB}_{2}-22.1$ volume-percent-SiC-5.9volume-percent- HfC. A key observation is that while thermal conductivities of all UHTCs studied are significantly different at room temperature, they converge to similar values at high temperatures. ${ }^{13}$ This is convenient from a design perspective because, independent of the UHTC used, all will perform in a similar manner at the working temperatures.

Figure 5 shows cross-section microstructures of $\mathrm{ZrB}_{2^{\prime}} \mathrm{ZS} 20$ and $\mathrm{ZS} 20-\mathrm{LaB}_{6}$. In-situ oxidation-resistant, refractory coatings have been generated on various UHTCs densified using SPS and containing rare-earth additives, such as $\mathrm{LaB}_{6}, \mathrm{La}_{2} \mathrm{O}_{3}$ and $\mathrm{Gd}_{2} \mathrm{O}_{3}$. Oxidation of $\mathrm{ZS} 20-\mathrm{LaB}_{6}$ for 1 hour at $1600^{\circ} \mathrm{C}$ in static air led to formation of a dense surface layer, up to 250 micrometers thick, of $\mathrm{ZrO}_{2}$ and rare-earth zirconates. With melting points well above $1600^{\circ} \mathrm{C}$, both phases remained solid throughout the oxidation process. Conversely, the oxidized surface of ZS20 without the rareearth additives comprised a porous $\mathrm{ZrO}_{2}$ layer up to only 10 micrometers thick covered by amorphous silica, which would have been liquid at $1600^{\circ} \mathrm{C}$. The low oxygen permeability of liquid silica suppresses excessive oxidation of ZS20 in static air at $1600^{\circ} \mathrm{C}$. However, in a hypersonic air stream this protective advantage would be lost quickly because of liquid silica removal by viscous flow. The oxygen permeabilities of
RE zirconates, although not as low as liquid silica, are still substantially lower than $\mathrm{ZrO}_{2}$. This, combined with the high melting point of RE zirconates, suggests that RE additions may be a useful approach to improving the oxidation resistance of UHTCs at intermediate temperatures in hypersonic air flows.

Testing methods and challenges

A large number of testing techniques are available for evaluating the hightemperature performance of UHTC materials. Laser heating/melting has been used extensively to study UHTCs and other ceramics used at extreme temperatures, including refractoriesand nuclear fuels. ${ }^{14}$ Defocused laser heating in air of $\mathrm{ZrB}_{2}$ - and $\mathrm{HfB}_{2}$-based UHTCs was conducted at TWI near Cambridge in the UK using either a Nd:YAG laser, capable of delivering a heat flux of up to approximately 20 megawatts per square meter, or a high-brightness ytterbium fiber laser with a 10-millimeterdiameter collimated beam and able to provide a heat flux up to 44 megawatts per square meter.

Photographs of $\mathrm{HfB}_{2}$-based UHTC samples laser tested under various conditions are shown in Figure 6. The top and bottom rows correspond to samples exposed to 8.2 and 15 megawatts per square meter heat flux for 60 seconds, respectively. For the former, the $\mathrm{HfB}_{2}-$ 20-percent-volume-SiC (HS20) sample largely retained its shape and size, but a 100-micrometer-thick white coating developed on the surface that detached from an intermediate oxide layer containing voids or cracks. The HS20weight-percent- $\mathrm{La}_{2} \mathrm{O}_{3}$ and $\mathrm{HfB}_{2}$ samples retained their original shape and size, with the former developing a thin oxide coating and the latter a thicker coating on exposed surfaces. For the 15.2 megawatt per square meter-tested samples, the $\mathrm{HfB}_{2}$ and $\mathrm{HS} 20$-2-weight-percent$\mathrm{La}_{2} \mathrm{O}_{3}$ largely retained their integrity, especially when compared with the significantbubblesand cratersobserved on the HS20.

Typical surface microstructures of HS20-LaB 6 laser-heated for $60 \mathrm{sec}-$ onds at 15.2 megawatt per square 

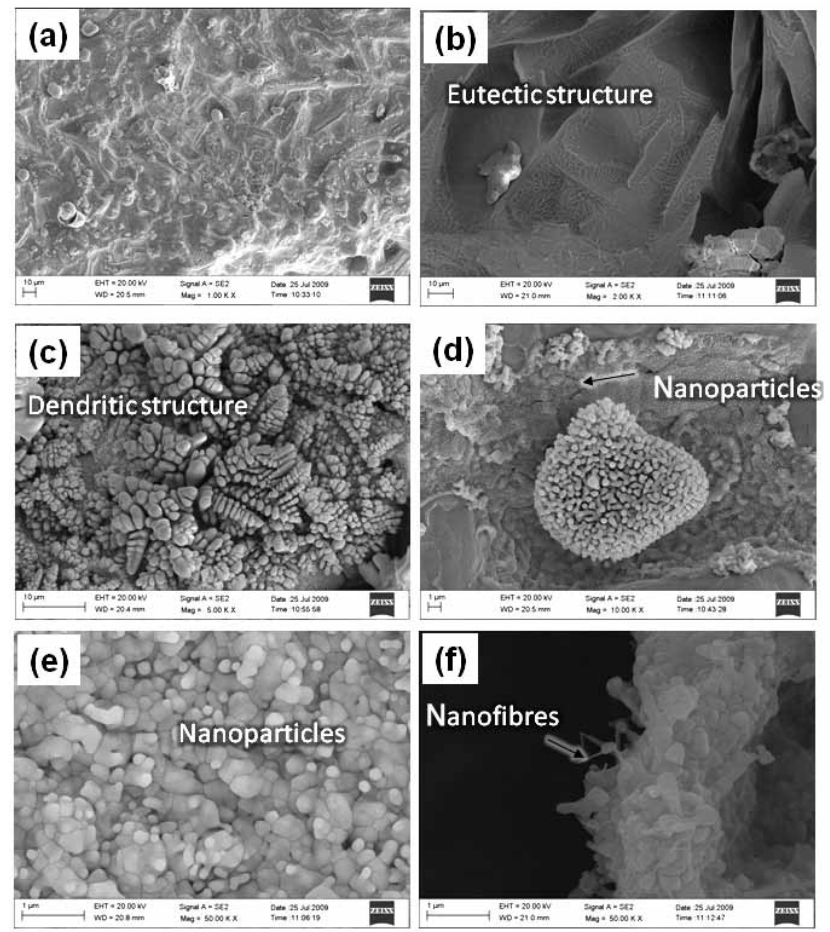

Figure 7 Surface morphology of HS20-5-weight-percent-LaB 6 sample laser tested for 60 seconds at 15.2 megawatts per square meter, showing (a) dense surface, (b) eutectic microstructure, (c) dendritic structure, (d) submicrometer-sized and nanometer-sized particles, (e) nanoparticles and (f) nanofibers.

meter are shown in Figure 7. Figure 7(a) reveals a dense microstructure-the very high heat flux has modified the structure and morphology of the surface significantly. Figure 7 (b) shows a region of the oxidized surface with a eutectic structure that is believed to have been composed of $\mathrm{HfB}_{2}$ and $\mathrm{HfO}_{2}$. EDS analysis confirmed the presence of hafnium, boron and oxygen. Because there is no phase diagram available for this system, the temperature at which this eutectic forms is unknown. Figure 7(c) shows a completely dendritic microstructure, which itself confirms that a large volume of melt was present on the surface. Presumably, because of the subsequent rapid solidification and influence of vapor phases, nanoparticles (Figures 7(d) and (e) and nanofibers (Figure $7(f))$ formed on the surface.

To evaluate the performance of UHTC samples at even higher temperatures, laser testing was performed using an extremely high heat flux of 44 megawatts per square meter, for 1 to 5 seconds, again in air. Figure 8 shows photographs after testing for 1 second. Except for the $\mathrm{HfB}_{2}$-2-weightpercent- $\mathrm{La}_{2} \mathrm{O}_{3}$ sample, all others were severely damaged, losing their shape and uniformity. The surfaces of all samples were black or dark grey in color. This might be attributed either to the solidification of $\mathrm{HfB}_{2}$ on the top surface (although why it should have survived being oxidized is unknown) or to the formation of a black oxide. The black layer can form as result of the formation of a nonstoichiometric oxide, particularly in the zirconium and hafnium oxide systems. The advantage of adding $\mathrm{TaSi}_{2}$ to UHTCs to

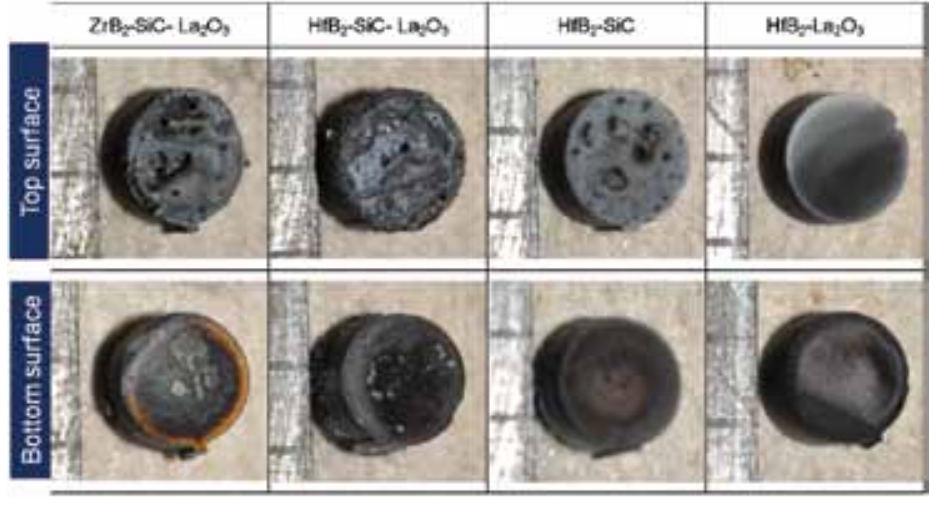

Figure 8 Photographs of UHTCs tested at 44 megawatts per square meter heat flux for 1 second using a defocused ytterbium laser.

form a black oxide to increase the emissivity is well-known.

Figure 9 shows SEM cross sections of samples laser tested at 44 megawatts per square meter for 1 second. These show that the $\mathrm{HfB}_{2}-2$-weight-percent- $\mathrm{La}_{2} \mathrm{O}_{3}$ sample appeared to perform better than the others, with a thin (approximately 100 micrometers) oxide coating forming and an absence of other defects, such as pores and cracks.

At heat fluxes up to 15.2 megawatts per square meter, $\mathrm{HfB}_{2}$-based ceramics perform better in terms of retaining structural integrity compared with $\mathrm{ZrB}_{2}$-based ceramics. In addition, $\mathrm{SiC}$ reinforcement and lanthanum-based additives

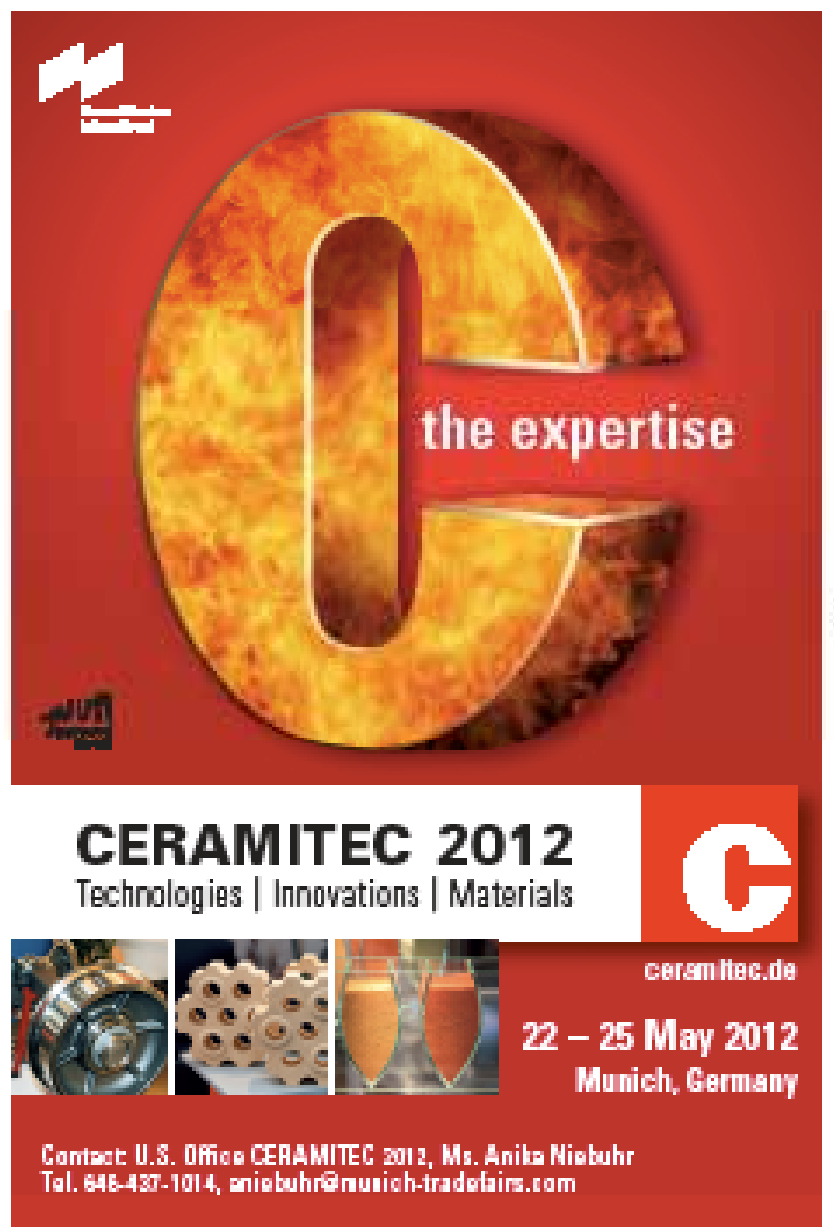

See us at ICACC'12 Expo Booth 402 


\section{UHTC composites for hypersonic applications}
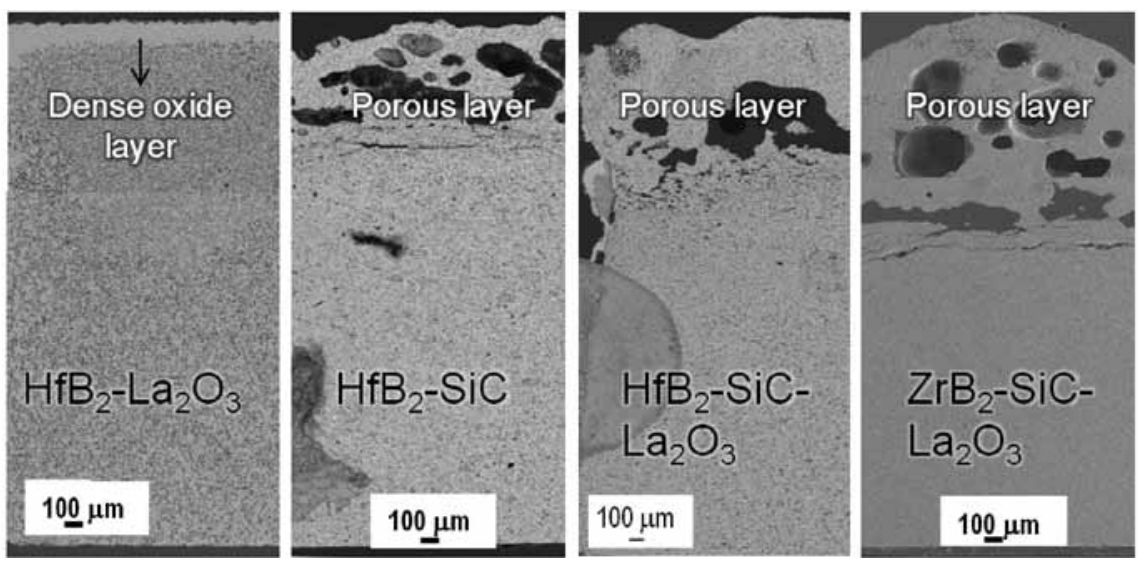

Figure 9 Comparison of cross-section microstructures of four samples laser tested at 44 megawatts per square meter for 1 second using a defocused ytterbium laser.

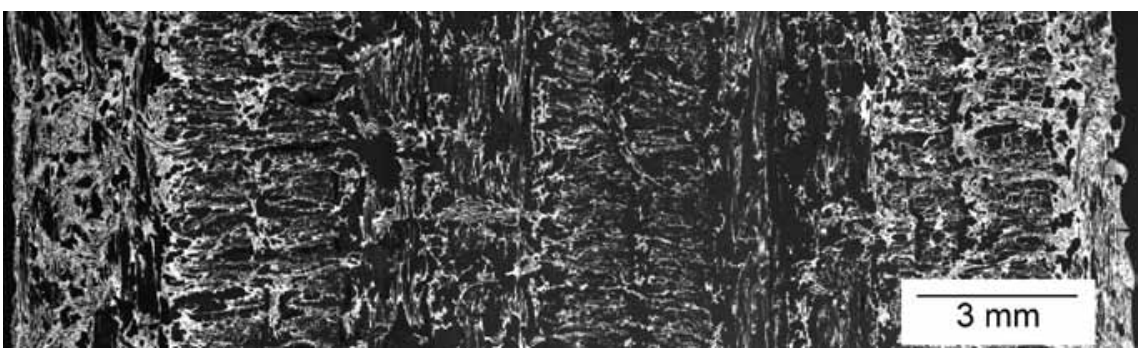

Figure 10 Powder distribution across the cross section of a vacuum-impregnated carbon-fiber- $\mathrm{HfB}_{2}$ composite.

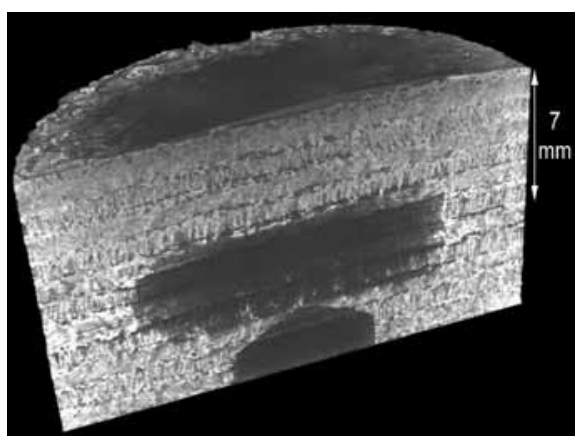

Figure 11 3D micro-CT cross section of a UHTC composite prepared by squeeze impregnation showing powder penetration. The dimensions of the composite were 30-millimeter-diameter 3 18-millimeter-thick. The dark area at the bottom is a hole drilled into the impregnated preform to allow a subsequent CVI stage to deposit carbon.

help to form intermediate layers with low oxygen permeability that appear to slow down the oxidation process. However, at very high heat fluxes, such as 44 megawatts per square meter, microstructural observation indicates that the $\mathrm{SiC}$ reinforcement and $\mathrm{La}_{2} \mathrm{O}_{3}$ additive do not help because they yield gases that further deteriorate the performance of the sample.

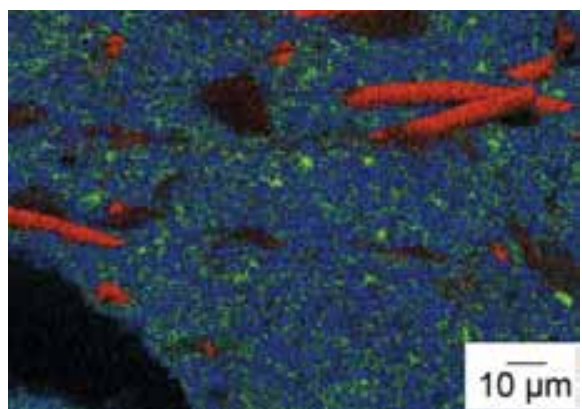

Figure 12 EDS mapping of carbon (red), silicon (green) and zirconium (blue) showing the distribution of UHTC powder within a carbon-fiber- $\mathrm{ZrB}_{2}-20$-volume-percent $\mathrm{SiC}$ composite.

\section{UHTC-carbon-fiber composites} and hybrid composites

Work at Loughborough is focused on impregnating carbon-fiber-based systems with UHTC powders. Carbon fibers are attractive because they can be formed readily into a preform of almost any configuration by winding, weaving, knitting, braiding or wrapping over a suitably formed mandrel..$^{15}$ There have been a number of attempts by researchers to prepare carbon-fiber-based composites for ultra-high-temperature applications. For example, Levine et al. ${ }^{16}$ examined composites containing
$\mathrm{HfB}_{2}$ and $\mathrm{SiC}$ powders in a study that also investigated the high-temperature performance of SiC-fiber-reinforced $\mathrm{ZrB}_{2}$-20-volume-percent-SiC composites (ZSS) at temperatures up to $1927^{\circ} \mathrm{C}$ for up to 100 minutes. ${ }^{17}$ The composites were prepared by a filament winding and slurry impregnation technique followed by hot pressing, and results were compared with $\mathrm{ZrB}_{2}-20$-volumepercent-SiC and $\mathrm{ZrB}_{2}-14$-volumepercent-SiC-30-volume-percent-carbon compositions containing no fiber reinforcement. Tang et al..$^{18}$ prepared various carbon-fiber UHTC powder composites using 2D carbon-fiber preforms and aqueous UHTC powder slurries based on $\mathrm{ZrB}_{2}, \mathrm{SiC}, \mathrm{HfC}$ and $\mathrm{TaC}$, which were infiltrated into the performs using a pressure-assisted technique. The impregnated composites were further densified by pyrocarbon deposition at $1000^{\circ} \mathrm{C}$ to $1100^{\circ} \mathrm{C}$ using a chemical vapor infiltration process. The UHTC powders concentrated in a 2-millimeter-deep layer at the surface. Hightemperature oxidation performance of the composites was measured using an oxyacetylene flame, and the $\mathrm{ZrB}_{2}$-based system displayed thebestresistanceafter 30 seconds at 3920 kilowatts per square meter and $2700^{\circ} \mathrm{C}$. Addition of $\mathrm{SiC}$ was found to improve the oxidation resistance only under the less demanding conditions of 2380 kilowatts per square meter and $1800^{\circ} \mathrm{C}$, albeit they were able to survive for 300 seconds.

Hybrid UHTC composites were fabricated at Loughborough using 30-millimeter-diameter 3 20-millimeterthick 2.5 D carbon-fiber preforms that contained 23-volume-percent fibers provided by Surface Transforms Ltd. in the UK. UHTC powder/phenolic resin/ acetone slurries were prepared by ball milling using alumina milling media for 48 hours. The UHTC compositions included $\mathrm{ZrB}_{2}, \mathrm{ZrB}_{2}$-20-volumepercent-SiC, $\mathrm{ZrB}_{2}-20$-volume-percent$\mathrm{SiC}-10$-volume-percent- $\mathrm{LaB}_{6}{ }_{6^{\prime}} \mathrm{HfB}_{2}$ and $\mathrm{HfC}$ while the phenolic resin had a carbon content of 45.5 percent. The carbon-fiber preforms were separately impregnated with the slurries using either a squeeze or vacuum impregnation technique and then dried in an 


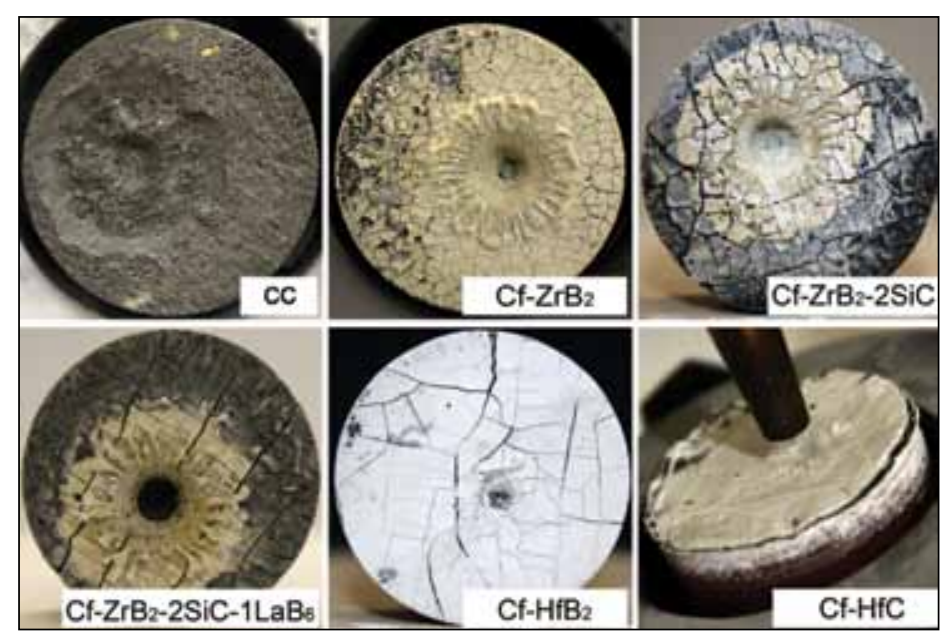

Figure 13 Comparison of carbon-carbon (CC) and carbon-fiber (Cf-) UHTC composites after 60 seconds oxyacetylene testing. Diameter of the composites was 30 millimeters.
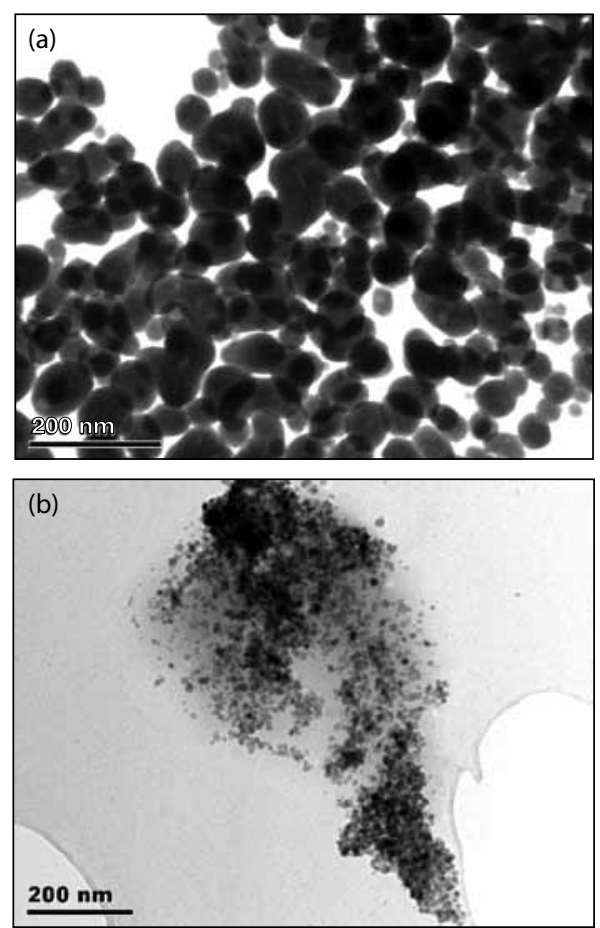

Figure 14 TEM images of (a) HfC particles and (b) $\mathrm{HfB}_{2}$ particles synthesized using a sol-gel approach.

oven at $75^{\circ} \mathrm{C}$ for 4 hours followed by curing at $125^{\circ} \mathrm{C}$ to $150^{\circ} \mathrm{C}$ for 2 hours. This cycle was repeated three times to maximize the amount of UHTC powder within each composite. After the third impregnation and curing, the samples were pyrolyzed at $900^{\circ} \mathrm{C}$ under flowing argon (99.998 percent pure) and further densified using chemical vapor infiltration of carbon. Benchmark carbon/ carbon composites also were prepared using chemical vapor infiltration of the preforms without UHTC powder
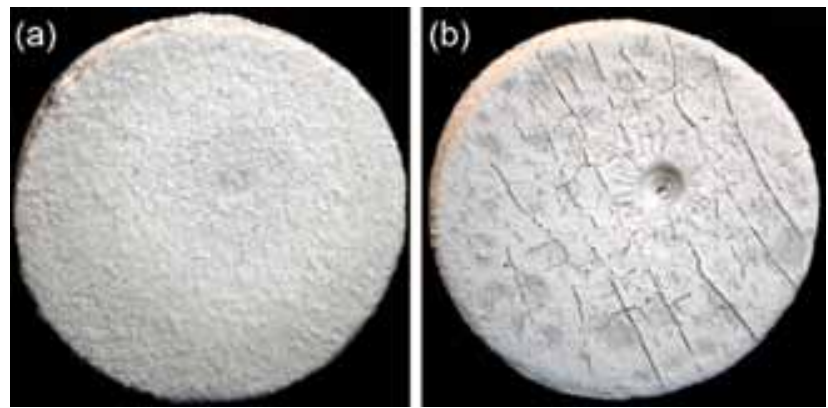

Figure 15 Carbon-fiber-HfB ${ }_{2}$ composites after oxyacetylene torch testing after (a) 60 seconds showing negligible erosion and (b) 140 seconds showing less than 2-millimeter erosion.

impregnation.

The result-

ing composites were examined using a range of techniques, including SEM, EDX and micro-CT to determine the depth of impregnation, powder distribution and the efficiency of powder mixing. The bulk density of the composites was measured using geometrical methods. The powder distribution across the cross section of a carbon-fiber- $\mathrm{HfB}_{2}$ UHTC composite (Figure 10) reveals that the preforms were fully impregnated from top to bottom, although the composites were found to be slightly denser near the circumference because of the UHTC powder slurry impregnation from the sides of the preform. Micro-CT analysis was performed on the impregnated preforms to determine the depth of penetration. A representative $3 \mathrm{D}$ cross-sectional image is given in Figure 11 of one of the carbon-fiber$\mathrm{ZrB}_{2}$ composites. The depth of impregnation was found to be approximately 7 millimeters from the top surface, which is greater than the 2-3 millimeter penetration achieved by Tang et al. ${ }^{18}$ Powder distribution results obtained using EDS analysis on the cross section of carbon-fiber- $\mathrm{ZrB}_{2}-2 \mathrm{SiC}$ composites revealed uniform mixing and distribution of the powder within the composite (Figure 12). In general, it was found that the vacuum impregnation technique yielded superior results to the squeeze impregnation route.

High-temperature performance of the composites was determined using an oxyacetylene torch test facility constructed at Loughborough University (see sidebar). Initially, the aim was simply to rank the UHTC composites according to their oxidation performance. However, subsequently the test was used to aid the development of superior composites.

The images of the preliminary composites after 60 seconds oxyacetylene torch testing are compared in Figure 13. As expected, the carbon-carbon composite was damaged over a wide area, approximately 20 -millimeter-diameter damagezone, whilethe performances of the carbon-fiber- $\mathrm{ZrB}_{2}$ and carbon-fiber$\mathrm{ZrB}_{2}$-20-volume-percent-SiC composites were similar to each other, with the damage being mainly focused over an approximately 5-millimeter-diameter area. There was more erosion damage for the $\mathrm{LaB}_{6}$ composite compared with the other $\mathrm{ZrB}_{2}$-containing composites. The high-temperatureflame penetrated the impregnated layer and attacked the carbon-carbon layer below. The addition of $\mathrm{LaB}_{6}$ was intended to improve the oxidation resistance through the formation of $\mathrm{La}_{2} \mathrm{Zr}_{2} \mathrm{O}_{7}$ pyrochlore structures at higher temperatures. ${ }^{10}$

Carbon-fiber- $\mathrm{HfB}_{2}$ and carbonfiber-HfC composites offered the best erosion protection, even though the UHTC powders were oxidized to $\mathrm{HfO}_{2}$ as expected. The presence of molten phases can be seen on all of the impregnated composites, independently confirming the temperature of the flame. The amount of melting was much lower in the $\mathrm{HfB}_{2}$-based composites than in those based on $\mathrm{ZrB}_{2}$ because of the higher melting temperature of $\mathrm{HfO}_{2}$ (approximately $2800^{\circ} \mathrm{C}$ ). ${ }^{11}$ The oxide layer formed on the carbon-fiber-HfC composite was less adherent than those on the other composites and fell off after the test, possibly because of the 


\section{UHTC composites for hypersonic applications}

absence of any glassy phases during the test and the build up of $\mathrm{CO} / \mathrm{CO}_{2}$ gas below the oxide layer.

Based on the initial tests, further research was focused on the two hafnium-based compositions because they showed the best high-temperature performance. Attempts were made to improve the UHTC slurry impregnation, and the lack of availability of $\mathrm{HfC}$ and $\mathrm{HfB}_{2}$ powders with submicrometer particle size was an issue. The average particle sizes of $\mathrm{HfC}$ and $\mathrm{HfB}_{2}$ from the two major European suppliers were more than 1 micrometer. Hence, research was initiated at Loughborough University to synthesize nanometersized $\mathrm{HfC}$ and $\mathrm{HfB}_{2}$ particles using sol-gel routes, which has now been achieved (Figure 14)..$^{19}$

Composites also were prepared by mixing powders of various particle sizes. The average bulk densities of the composites were 2.4 and 2.2 grams per cubic centimeter for $\mathrm{HfB}_{2}$ - and $\mathrm{HfC}$ based composites, respectively, which is higher than the densities achieved with commercial powder alone. With the powder mixture and using vacuum impregnation, it is now possible to prepare carbon-fiber- $\mathrm{HfB}_{2}$ composites that show no erosion after 60 seconds at approximately $2700^{\circ} \mathrm{C}$ and minimum erosion after 140 seconds at the same temperature (Figure 15). ${ }^{20}$

Thus, the UHTC powder-impregnated carbon-fiber composites offer excellent high-temperature oxidation protection when tested using an oxyacetylene torch. Current efforts focus on determining the mechanical properties of UHTC composites at room and elevated temperatures and on the preparation of sharp leading-edge-shaped composites for performance testing. Trials also are in progress to sinter the impregnated composites using the SPS technique. Another novel approach being evaluated is the preparation of hybrid UHTC composites incorporating a UHTC monolithic layer to further improve the high-temperature oxidation resistance.

\section{Summary and future work}

Real progress has been made in the quest to develop materials capable of withstanding the difficult conditions for hypersonic space travel. UHTC research at Imperial College and Loughborough University has demonstrated the preparation of fully dense UHTC monoliths for a range of various compositions and of carbonfiber-UHTC composites with significant powder impregnation. Key aspects include the following.

- The microstructures formed at UHTs are complex and heterogeneous.

- Thermal diffusivities in composite systems tend to merge to similar values at UHTs, whereas CTEs remain comparatively large.

- At high heat fluxes (approximately 44 megawatts per square meter) $\mathrm{SiC}$ and lanthanum-based additives lead to gas evolution and deterioration in laser test performance.

- The oxyacetylene torch test is useful for rapid screening of UHTC composites based on UHT oxidation performance.

- Carbon-fiber-HfB ${ }_{2}$ composites showed the best oxidation resistance above $2500^{\circ} \mathrm{C}$.

- Nanocrystalline $\mathrm{HfB}_{2}$ and $\mathrm{HfC}$ powders have been synthesised using sol-gel routes and will be impregnated into carbon-fiber preforms.

Future work will be focused primarily on joining UHTC monoliths with the UHTC composites to take maximum advantage of the two approaches. The goal is to prepare prototype leading edge components and plates for subsequent in-flight testing.

\section{Acknowledgements}

The authors thank the UK's Defence Science and Technology Laboratory (DSTL) for providing the financial support for this work under contract numbers DSTLX-1000015267 and DSTLX1000015413 as well as the US Air Force Research Laboratory's Materials and Manufacturing Directorate for ongoing collaborations.

\section{About the authors}

A. Paul, S. Venugopal, J.

Binner and B. Vaidhyanathan are affiliated with the Department of Materials, Loughborough University, Loughborough, UK. D.D. Jayaseelan,
E. Zapata-Solvas and W.E. Lee are affiliated with the Centre for Advanced Structural Ceramics, Department of Materials, Imperial College London, S Kensington Campus, London, UK. A. Heaton and P. Brown are affiliated with DSTL, Porton Down, Wiltshire, UK. Corresponding authors: W.E. Lee, w.e.lee@imperial.ac.uk; J. Binner, j.binner@boror.ac.uk

\section{References}

'C. Tallon, S. Slater, A. Gillen, C. Wood and J. Turner, "Ceramic Materials for Hypersonic Applications," Materials Australia, [July] 28-32 (2011).

${ }^{2}$ K. Forsthoefel and L.G. Sneddon, "Precursor Routes to Group 4 Metal Borides, and Metal Boride/Carbide and Metal Boride/ Nitride Composites," J. Mater. Sci., 39 [19] 6043-49 (2004).

${ }^{3}$ E. Wuchina, M. Opeka, S. Causey, K. Buesking, J. Spain, A. Cull, J. Routbort and E. Guitierrez-Mora, "Designing for UltrahighTemperature Applications: The Mechanical and Thermal Properties of $\mathrm{HfB}_{2}, \mathrm{HfC}_{\mathrm{x}^{\prime}} \mathrm{HfN}_{\mathrm{x}}$ and alpha-Hf(N)," J. Mater. Sci., 39 [19] 5939-49 (2004).

${ }^{4} \mathrm{~F}$. Monteverde and A. Bellosi, "Oxidation of $\mathrm{ZrB}_{2}$-Based Ceramics in Dry Air," J. Electrochem. Soc., 150 [11] B552-B559 (2003).

${ }^{5}$ W.G. Fahrenholtz, G.E. Hilmas, A.L. Chamberlain and J.W. Zimmermann, "Processing and Characterization of $\mathrm{ZrB}_{2}$-Based Ultra-High-Temperature Monolithic and Fibrous Monolithic Ceramics," J. Mater. Sci., 39 [19] 5951-57 (2004).

${ }^{6}$ E.J. Wuchina and M.M. Opeka, "Oxidation of Hf-Based Ceramics,"High-TemperatureCorrosion and Materials Chemistry, 99 [38] 477-88 (2000).

${ }^{7}$ A.G. Metcalfe, N.B. Elsner, D.T. Allen, E. Wuchina, M. Opeka and E. Opila, "Oxidation of Hafnium Diboride," High Temperature Corrosion and Materials Chemistry, 99 [38] 489-501 (2000).

${ }^{8}$ E. Eakins, D.D. Jayaseelan and W.E. Lee, "Toward OxidationResistant ZrB - -SiC Ultra-High-Temperature Ceramics," Metall. Mater. Trans. A-Phys. Metall. Mater. Sci., 42A, 878-87 (2011). ${ }^{9}$ E.J. Opila and M.C. Halbig, "Oxidation of ZrB -SiC"; pp. 221-28 in 25th Annual Conference on Composites, Advanced Ceramics, Materials, and Structures: A: Ceramic Engineering and Science Proceedings, Vol. 22, Issue 3. Edited by M. Singh and T. Jessen. Wiley, New York, 2001. (Published online March 28, 2008.)

${ }^{10}$ D.D. Jayaseelan, E. Zapata-Solvas, P. Brown and W.E. Lee, "In-Situ Formation of Oxidation-Resistant Refractory Coatings on SiC-Reinforced $\mathrm{ZrB}$ Ultra-High-Temperature Ceramics (UHTCs)," J. Am. Ceram. Soc. (to be published 2012).

"T.A. Parthasarathy, R.A. Rapp, M. Opeka and R.J. Kerans, "A Model for the Oxidation of $\mathrm{ZrB}_{2^{\prime}}, \mathrm{HfB}_{2}$ and $\mathrm{TiB}_{2^{\prime}}$ 'Acta Mater., 55 5999-6010 (2007).

${ }^{12} \mathrm{~F}$. Monteverde, “Progress in the Fabrication of Ultra-HighTemperature Ceramics: In-Situ Synthesis, Microstructure and Properties of a Reactive Hot-Pressed HfB $-\mathrm{SiC}$ Composite," Compos. Sci. Technol., 65 [11-12] 1869-79 (2005).

${ }^{13}$ E. Zapata-Solvas, D.D. Jayaseelan, P. Brown and W.E. Lee, unpublished work.

${ }^{14}$ H.F. Jackson, D.D. Jayaseelan, D. Manara, C.P. Casoni and W.E. Lee, "Laser Melting of Zirconium Carbide: Determination of Phase Transitions in Refractory Ceramic Systems," J. Am. Ceram. Soc., 94 [10] 3561-69 (2011).

${ }^{15} \mathrm{~A}$. Sayir, "Carbon-Fiber-Reinforced Hafnium Carbide Composite," J. Mater. Sci., 39, 5995-6003 (2004).

${ }^{16}$ S.R. Levine, E.J. Opila, R.C. Robinson and J.A. Lorincz, "Characterization of an Ultra-High-Temperature Ceramic Composite," NASA Report No. TM 2004-213085, 2004. ${ }^{17}$ S.R. Levine, E.J. Opila, M.C. Halbig, J.D. Kiser, M. Singh and J.A. Salem, "Evaluation of Ultra-High-Temperature Ceramics for Aeropropulsion Use," J. Eur. Ceram. Soc., 22 [14-15] 2757-67 (2002).

${ }^{18}$ S.F. Tang, J.Y. Deng, S. Wang, W.C. Liu, and K. Yang, "Ablation Behaviors of Ultra-High-Temperature Ceramic Composites" Mater. Sci. Eng. A, 465, 1-7 (2007).

${ }^{19}$ S. Venugopal, A. Paul, B. Vaidhyanathan, J. Binner, A. Heaton and P. Brown, "Nano-Crystalline Ultra-High-Temperature $\mathrm{HfB}_{2}$ and $\mathrm{HfC}$ Powders and Coatings Using a Sol-Gel

Approach,"Advanced Ceramic Coatings and Materials for Extreme Environments: Ceram. Eng. Sci. Proc., Volume 32, Edited By D. Zhu, H-T. Lin, Y. Zhou, S. Widjaja and D. Singh, Ed. ${ }^{20}$ A. Paul, S. Venugopal, J. Binner, B. Vaidhyanathan, A. Heaton and P. Brown, "Effect of UHTC Powder Particle Size and Preform Fibre Orientation on the High-Temperature Performance of UHTC Composites," (submitted J. Eur. Ceram. Soc. 2011). 


\section{Oxyacetylene torch testing of materials}

Many testing techniques are available for evaluating high-temperature performance of UHTC materials, including static furnace oxidation testing, laser ablation testing, oxyacetylene torch testing, plasma wind tunnel testing, strip heater testing, arc jet testing and scramjet testing. ${ }^{*}$ None of these test methods alone can reproduce all the conditions experienced during hypersonic flight. Oxyacetylene torch testing, however, is a quick and inexpensive technique to evaluate the high-temperature performance of materials.

At Loughborough University in the UK, an oxyacetylene-torch-testing facility has been built that is equipped to perform high-temperature oxidation testing of UHTC materials at temperatures up to about $2800^{\circ} \mathrm{C}$, while recording the temperature and temperature distribution during testing (Figure 1). Heating rates of up to approximately $500^{\circ} \mathrm{C}$ per second can be achieved.

An oxygen-rich flame was chosen for testing the composites, and this was achieved by supplying stoichiometrically excess oxygen: acetylene to oxygen ratio is $1: 1.35$. The UHTC samples are fixed in a water-cooled graphite holder with three graphite bolts. To date, tests have been conducted for 30 seconds up to 360 seconds, although tests of shorter or longer duration are possible. During the test, the temperature is measured using a two-color pyrometer (Marathon MR1SCSF, Raytek $\mathrm{GmbH}$, Berlin, Germany), and the temperature distribution is measured using an infrared thermal-imaging camera (Thermovision A40 FLIR Systems AB, Danderyd, Sweden). The two-color pyrometer is capable of recording temperatures up to $3000^{\circ} \mathrm{C}$, and the thermal imaging camera can record temperatures up to $1500^{\circ} \mathrm{C}$. By adding an IR neutral density filter, the camera can record temperatures up to $2800^{\circ} \mathrm{C}$. The back surface temperature of the samples is recorded using a K-type thermocouple connected to a data logger.

Figure 2 shows an image taken during the oxyacetylene torch testing of one of the UHTC composites along with another image taken immediately after extinguishing the flame. It is a very aggressive test because it involves high temperature, high-velocity gas flow and oxidizing gases.

The temperature distribution recorded

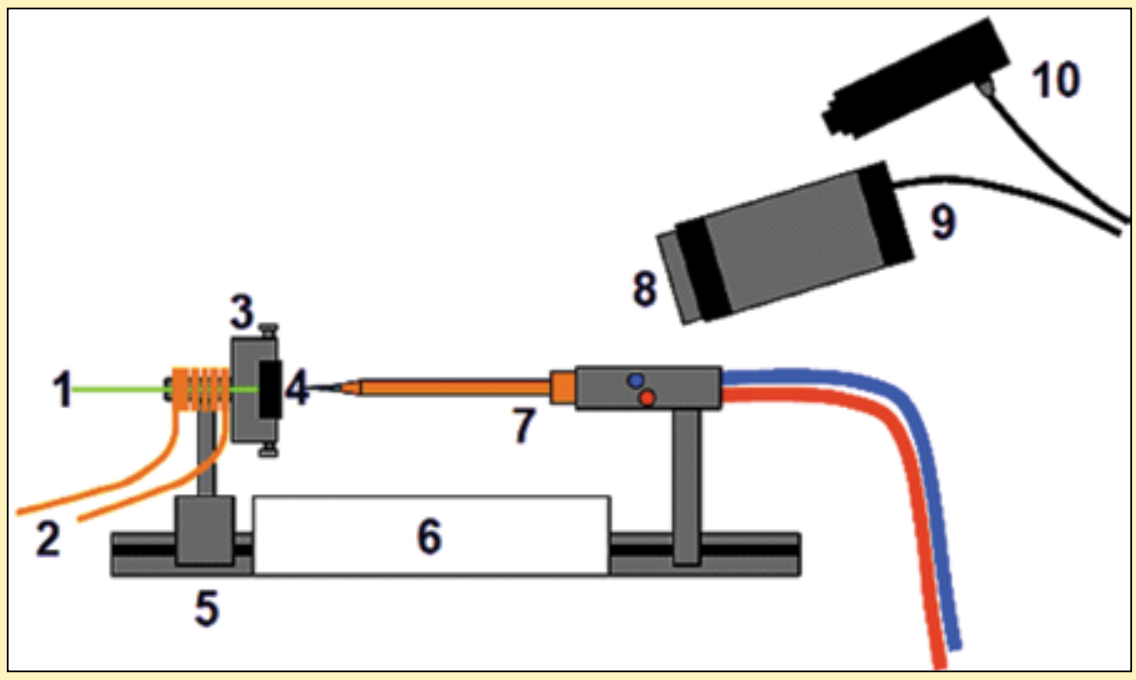

Figure 1 Oxyacetylene test set up at Loughborough University: (1) back face thermocouple, (2) water cooling system, (3) sample holder, (4) sample, (5) sample guide, (6) protective insulation, (7) oxyacetylene torch, (8) neutral density filter, (9) thermal imaging camera and (10) two-color pyrometer.

during a 6-minute testing of a UHTC composite is shown in Figure 3. The figure shows a very high temperature gradient, and the composite samples survived without much damage.

Planned improvements include increasing the temperature capability and uniformity of the torch by using a multiflame nozzle, adding a computer controller to automate the whole testing process, including sample movement, and the ability to provide rapid cooling via applying a jet of cold nitrogen gas.

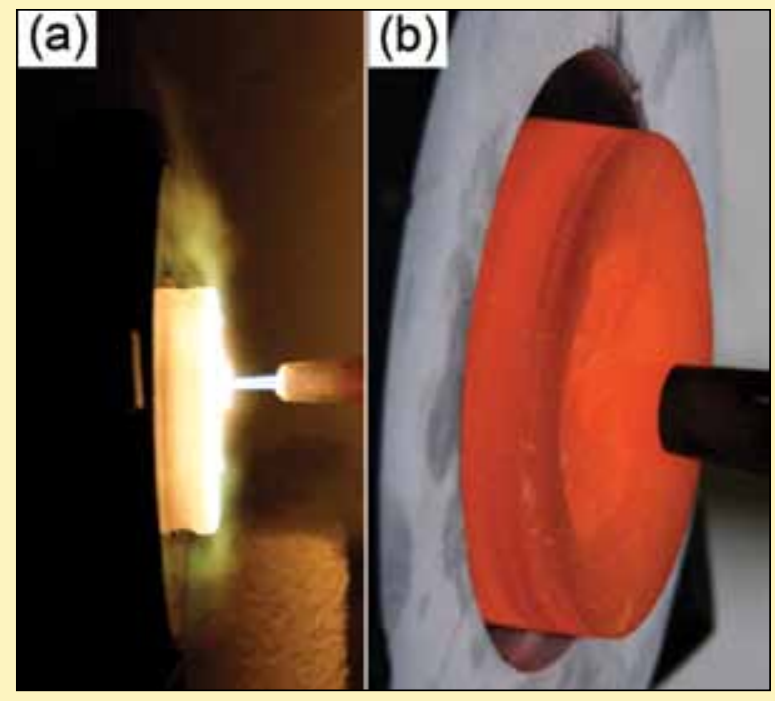

Figure 2 Image showing (a) sample being tested using an oxyacetylene flame and (b) immediately after the test.

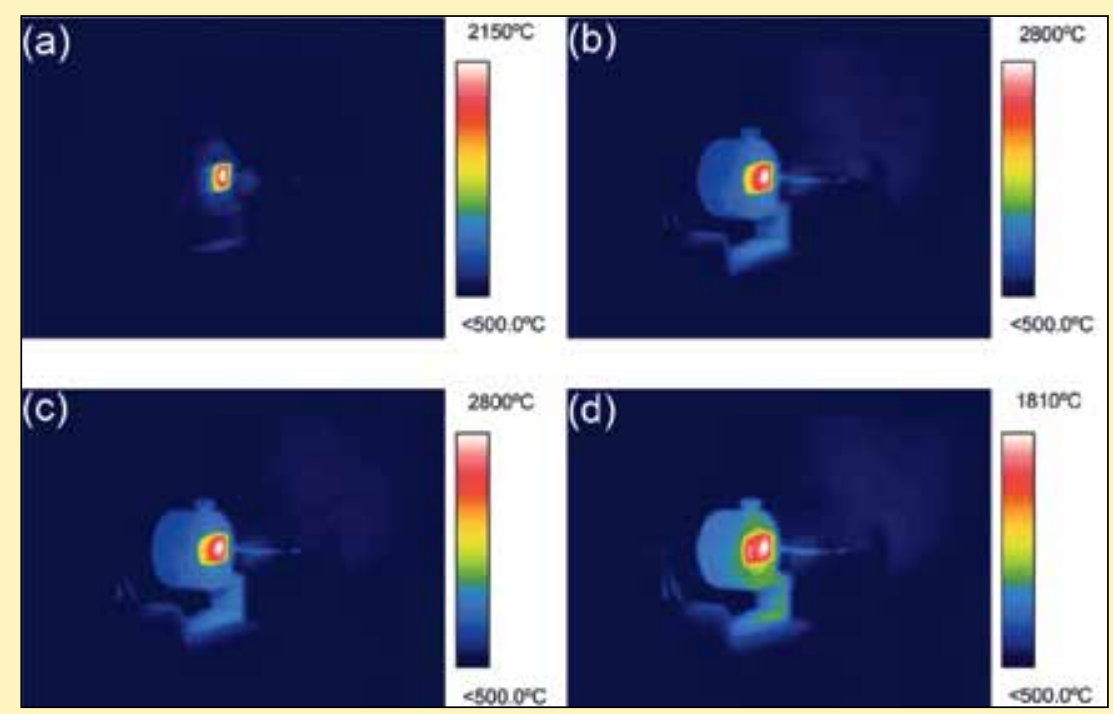

Figure 3 Temperature distribution during oxyacetylene torch testing: (a) beginning of the test, (b) at 3 minutes, (c) at 6 minutes and (d) immediately after extinguishing the flame. 


\section{Oxyacetylene torch testing of materials}

\section{References}

II.G. Talmy, J.A. Zaykoski and C.A. Martin, "Flexural creep deformation of $\mathrm{ZrB}_{2} / \mathrm{SiC}$ Ceramics in Oxidizing Atmosphere," J. Am. Ceram. Soc., 91, 1441-7 (2008).

2.G. Talmy, J.A. Zaykoski and M.M. Opeka, "High-Temperature Chemistry and Oxidation of $\mathrm{ZrB}_{2}$ Ceramics Containing $\mathrm{SiC}, \mathrm{Si}_{3} \mathrm{~N}_{4^{\prime}}, \mathrm{Ta}_{5} \mathrm{Si}_{3}$, and $\mathrm{TaSi}_{2^{\prime}}, \mathrm{J}$. Am. Ceram. Soc., 91, 2250-7 (2008).

${ }^{3}$ D. Sciti, V. Medri and L. Silvestroni, "Oxidation Behaviour of $\mathrm{HfB}_{2}-15$ vol.\% $\mathrm{TaSi}_{2}$ at Low, Intermediate and High Temperatures," Scr. Mater., 63, 601-4 (2010).

${ }^{4} \mathrm{C}$. Carney, "Oxidation Resistance of Hafnium Diboride-Silicon Carbide from 1400 to $2000^{\circ} \mathrm{C}$," J. Mater. Sci., 44, 567381 (2009).

${ }^{5}$ C.M. Carney, P. Mogilvesky and T.A. Parthasarathy, "Oxidation Behavior of Zirconium Diboride Silicon Carbide Produced by the Spark Plasma Sintering Method," J. Am. Ceram. Soc., 92, 2046-52 (2009).

${ }^{6}$ C.M. Carney, T.A. Parthasarathy and M.K. Cinibulk, "Oxidation Resistance of Hafnium Diboride Ceramics with Additions of Silicon Carbide and Tungsten Boride or Tungsten Carbide," J. Am. Ceram. Soc., 94, 2600-7 (2011).

${ }^{7}$ W. Han, P. Hu, X. Zhang, J. Han and S. Meng, "High-Temperature Oxidation at $1900^{\circ} \mathrm{C}$ of $\mathrm{ZrB}_{2}-\mathrm{xSiC}$ UltrahighTemperature Ceramic Composites," J. Am. Ceram. Soc., 91, 3328-34 (2008).

${ }^{8} \mathrm{P}$. Hu, X. Zhang, J. Han, X. Luo and S. $\mathrm{Du}$, "Effect of Various Additives on the Oxidation Behavior of $\mathrm{ZrB}_{2}$-Based UltraHigh-Temperature Ceramics at $1800^{\circ} \mathrm{C}$, J. Am. Ceram. Soc., 93, 345-9 (2010).

${ }^{9} \mathrm{P}$. Lespade, N. Richet and P. Goursat, "Oxidation Resistance of $\mathrm{HfB}_{2}-\mathrm{SiC}$ Composites for Protection of Carbon-Based Materials," Acta Astronaut., 60, 858-64 (2007).

${ }^{10}$ R. Licheri, R. Oru, C. Musa, A. Locci and G. Cao, "Spark Plasma Sintering of $\mathrm{ZrB}_{2}$ and $\mathrm{HfB}_{2}$-Based Ultra High Temperature Ceramics Prepared by SHS," International Journal ofSelf-Propagating High-Temperature Synthesis, 18, 15-24 (2009).

${ }^{11}$ M. Mallik, K.K. Ray and R. Mitra, "Oxidation Behavior of Hot Pressed $\mathrm{ZrB}_{2}-$ $\mathrm{SiC}$ and $\mathrm{HfB}_{2}-\mathrm{SiC}$ Composites," J. Eur. Ceram. Soc., 31, 199-215 (2011).
${ }^{12} \mathrm{~F}$. Monteverde and A. Bellosi, "The Resistance to Oxidation of an $\mathrm{HfB}_{2}-\mathrm{SiC}$ Composite," J. Eur. Ceram. Soc., 25, 1025 31 (2005).

${ }^{13}$ D. Ni, G. Zhang, F. Xu and W. Guo, "Initial Stage of Oxidation Process and Microstructure Analysis of $\mathrm{HfB}_{2}-20$ vol.\% $\mathrm{SiC}$ Composite at $1500^{\circ} \mathrm{C}$, Scr. Mater., 64 , 617-20 (2011).

${ }^{14} \mathrm{H}$. Petla, E.P. Renova, A. Bronson, J.F. Chessa and N. Maheswaraiah, "A Computational Analysis of a $\mathrm{ZrO}_{2}-\mathrm{SiO}_{2}$ Scale for a $\mathrm{ZrB}_{2}-\mathrm{ZrC}-\mathrm{Zr}$ Ultrahigh Temperature Ceramic Composite System," J. Eur. Ceram. Soc., 30, 2407-18 (2010).

${ }^{15}$ A. Rezaie, W.G. Fahrenholtz and G.E. Hilmas, "Oxidation of Zirconium DiborideSilicon Carbide at $1500^{\circ} \mathrm{C}$ at a Low Partial Pressure of Oxygen," J. Am. Ceram. Soc., 89, 3240-5 (2006).

${ }^{16}$ C. Tian, D. Gao, Y. Zhang, C. Xu, Y. Song and X. Shi, "Oxidation Behaviour of Zirconium Diboride-Silicon Carbide Ceramic Composites under Low Oxygen Partial Pressure," Corros. Sci., In Press, Corrected Proof.

${ }^{17}$ M. Wang, C. Wang, L. Yu, Y. Huang and $\mathrm{X}$. Zhang, "Oxidation Behavior of $\mathrm{SiC}$ Platelet-Reinforced $\mathrm{ZrB}_{2}$ Ceramic Matrix Composites," Int. J. Appl. Ceram. Techn., DOI:10.1111/j.1744-7402.2011.02647.x, (2011).

${ }^{18}$ X. Zhang, L. Xu, S. Du, W. Han and J. Han, "Preoxidation and Crack-Healing Behavior of $\mathrm{ZrB}_{2}-\mathrm{SiC}$ Ceramic Composite," J. Am. Ceram. Soc., 91, 4068-73 (2008).

${ }^{19}$ H.F. Jackson, D.D. Jayaseelan, W.E. Lee, et al., "Laser Melting of Spark Plasma-Sintered Zirconium Carbide: Thermophysical Properties of a Generation IV Very HighTemperature Reactor Material," Int. J. Appl. Ceram. Techn., 7, 316-26 (2010).

${ }^{20}$ H.F. Jackson, D.D. Jayaseelan, D. Manara, C.P. Casoni and W.E. Lee, "Laser Melting of Zirconium Carbide: Determination of Phase Transitions in Refractory Ceramic Systems," J. Am. Ceram. Soc., 94, 3561-69 (2011).

${ }^{21}$ Z. Chen, D. Fang, Y. Miao and B. Yan, "Comparison of Morphology and Microstructure of Ablation Centre of C/ $\mathrm{SiC}$ Composites by Oxy-Acetylene Torch at

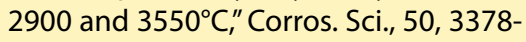
81 (2008).

${ }^{22}$ Z. Chen and B. Yan, "Morphology and Microstructure of Three-Dimensional Orthogonal C/SiC Composites Ablated by an Oxyacetylene Flame at $2900^{\circ} \mathrm{C}_{\text {, }}$ Int. J.
Appl. Ceram. Techn., 6, 164-70 (2009).

${ }^{23}$ S.R. Levine, E.J. Opila, R.C. Robinson and J.A. Lorincz, "Characterization of an Ultra-High Temperature Ceramic Composite," NASA TM-2004-213085, 1-26 (2004).

${ }^{24}$ J.C. Han, X.D. He and S.Y. Du, "Oxidation and Ablation of 3D CarbonCarbon Composite at up to $3000^{\circ} \mathrm{C}$," Carbon, 33, 473-8 (1995).

${ }^{25}$ J. Han, P. Hu, X. Zhang, S. Meng and W. Han, "Oxidation-Resistant $\mathrm{ZrB}_{2}-\mathrm{SiC}$ Composites at $2200^{\circ} \mathrm{C}$," Composites Sci. Technol., 68, 799-806 (2008).

${ }^{26}$ X. Li, J. Shi, H. Zhang, G. Zhang, Q. Guo and L. Liu, "Ablation Resistance and Mechanical/ Conductive Properties of $\mathrm{ZrB}_{2}$ Reinforced Carbon Based Composites," Journal of Composite Materials, 41, 353-66 (2007).

${ }^{27}$ P. Mark, "Oxidation Resistant HfC-TaC Rocket Thruster for High Performance Propellants," NASA report NAS3-27272, 1-24 (1999).

${ }^{28}$ G.M. Song, Y.J. Wang and Y. Zhou, “Elevated Temperature Ablation Resistance and Thermophysical Properties of Tungsten Matrix Composites Reinforced with $\mathrm{ZrC}$ particles," J. Mater. Sci., 36, 4625-31 (2001).

${ }^{29} \mathrm{G}$. Song, Y. Zhou and Y. Wang, “Effect of Carbide Particles on the Ablation Properties of Tungsten Composites," Mater Charact, 50, 293-303 (2003).

${ }^{30}$ S. Tang, J. Deng, S. Wang, W. Liu and K. Yang, "Ablation Behaviors of UltraHigh Temperature Ceramic Composites," Materials Science and Engineering: A, 465, 1-7 (2007).

${ }^{31} \mathrm{~F}$. Monteverde and R. Savino, "Stability of Ultra-High-Temperature $\mathrm{ZrB}_{2}-\mathrm{SiC}$ Ceramics Under Simulated Atmospheric Re-Entry Conditions," J. Eur. Ceram. Soc., 27, 4797-805 (2007).

${ }^{32}$ F. Monteverde, R. Savino, M.D.S. Fumo and A. Di Maso, "Plasma Wind Tunnel Testing of Ultra-High Temperature $\mathrm{ZrB}_{2}$-SiC Composites Under Hypersonic Re-Entry Conditions," J. Eur. Ceram. Soc., 30, 2313-21 (2010).

${ }^{33}$ R. Savino, M. De Stefano Fumo, D. Paterna, A. Di Maso and F. Monteverde, "Arc-Jet Testing of Ultra-HighTemperature-Ceramics," Aerospace Science and Technology, 14, 178-87 (2010).

${ }^{34}$ S.N. Karlsdottir, J.W. Halloran, F. Monteverde and A. Bellosi, “Oxidation 
of $\mathrm{ZrB}_{2}-\mathrm{SiC}$ : Comparison of Furnace Heated Coupons and Self-Heated Ribbon Specimens," pp. 327-36 in Mechanical Properties and Performance of Engineering Ceramics and Composites III. John Wiley \& Sons, Inc., 2007; 2009.

${ }^{35}$ S.N. Karlsdottir and J.W. Halloran, "Rapid Oxidation Characterization of Ultra-High Temperature Ceramics," J Am Ceram Soc., 90, 3233-8 (2007).

${ }^{36}$ S. Gangireddy, S.N. Karlsdottir, S.J. Norton, J.C. Tucker and J.W. Halloran, "In Situ Microscopy Observation of Liquid Flow, Zirconia Growth, and CO Bubble Formation during High Temperature Oxidation of Zirconium Diboride-Silicon Carbide," J. Eur. Ceram. Soc., 30, 2365-74 (2010).

${ }^{37}$ M. Gasch, D. Ellerby, E. Irby, S. Beckman, M. Gusman and S. Johnson, "Processing, Properties and Arc Jet Oxidation of Hafnium Diboride/Silicon Carbide Ultra High Temperature Ceramics," J. Mater. Sci., 39, 5925-37 (2004).

${ }^{38} \mathrm{E}$. Opila, S. Levine and J. Lorincz, "Oxidation of $\mathrm{ZrB}_{2}$ - and $\mathrm{HfB}_{2}$-Based UltraHigh Temperature Ceramics: Effect of Ta Additions," J. Mater. Sci., 39, 5969-77 (2004).

${ }^{39} \mathrm{X}$. Zhang, P. Hu, J. Han and S. Meng, "Ablation Behavior of $\mathrm{ZrB}_{2}-\mathrm{SiC}$ Ultra High Temperature Ceramics under Simulated Atmospheric Re-Entry Conditions," Composites Sci. Technol., 68, 1718-26 (2008).

${ }^{40}$ T.H. Squire and J. Marschall, "Material Property Requirements for Analysis and Design of UHTC Components in Hypersonic Applications," J. Eur. Ceram. Soc., 30, 2239-51 (2010).

${ }^{41}$ T.A. Parthasarathy, M.D. Petry, G. Jefferson, M.K. Cinibulk, T. Mathur and M.R. Gruber, "Development of a Test to Evaluate Aerothermal Response of Materials to Hypersonic flow Using a Scramjet Wind Tunnel," Int. J. Appl. Ceram. Techn., 8, 832-47 (2011). 